\title{
Digitization of Indian Education Process: A Hope or Hype
}

\author{
Prof. Nivedita Jha ${ }^{1}$, Prof. Veena Shenoy ${ }^{2}$ \\ ${ }^{1,2}$ Assistant Professor Krupanidhi School of Management
}

\begin{abstract}
Education system creates hope and it should never aim at creating mere hypes. Over a period of time many changes have occurred in different sectors of economy including the education system. Education sector unlike any other sector has seen many stages in its evolution. From Guru-Shishya system of conducting the class in open garden under the trees to closed class room lectures, presentation form of teaching with the aid of LCD touch-screen projector to online notes and now instant Whatsapp messages is the buzzword among the students. Whatsapp has gained the status of being authentic formal means of communication among the students and the academicians. Screenshots have taken off the business of many of the photocopy outlets operating within many school and college premises. Indian subcontinent is comprised of diverse population belonging to various ethnic and cultural groups. Apart from these differences, the most visible difference that makes a direct impact on the Indian education system is the diversity in purchasing power and affordability of the Indians. This article is aimed at analyzing the nature of the modern education process in India where diversity is seen not only in culture and ethnicity but also in purchasing power and affordability of the Indian people.
\end{abstract}

Keywords: Digitization, Cloud Learning, Education, Digital Education, Technology etc.

\section{Introduction}

The only constant is change and mankind is in a period of rapid technologically driven change"

The main reason for adopting many technologies is motivational, to take advantage of theInterest of learners. Twitter ${ }^{\mathrm{TM}}$ can be used for education but how much meaningful learning can be packed in 140 characters or less! What society and individuals need is hope, not hype!

India is a vast country with much diversity - in culture, language, heritage etc. and so is its education system. We have schools with all digitised air-conditioned classrooms as well as the transportation; there are schools which believe in emphasising on value education by following Guru Kul system where students are taught under the trees despite of having world-class infrastructure. At the same time there are schools which emphasise on books and physical development of students by conducting in-house activities whereas others can afford international exchange programs and have been able to send their students even to NASA. At the same time we have schools where students struggle for books.

India holds an important place in the global education industry. The country has more than 1.4 million schools with over 227 million students enrolled and more than 36,000 higher education institutes. India has one of the largest higher education systems in the world. However, there is still a lot of potential for further development in the education system.

India's online education market size is expected to touch US\$ 40 billion by 2017. An RNCOS report titled, 'Booming Distance Education Market Outlook 2018' expects the distance education market in India to grow at a compound annual growth rate (CAGR) of around 34 per cent during 2013-14 to 2017-18. Moreover, the aim of the government to raise its current gross enrolment ratio to 30 per cent by 2020 will also boost the growth of the distance education in India.

The education sector in India is poised to witness major growth in the years to come as India will have world's largest tertiary-age population and second largest graduate talent pipeline globally by the end of 2020 . As of now the education market is worth US\$ 100 billion. Currently, higher education contributes 59.7 per cent of the market size, school education 38.1 per cent, pre-school segment 1.6 per cent, and technology and multimedia the remaining 0.6 per cent.

Higher education system in India has undergone rapid expansion. Currently, India's higher education system is the largest in the world enrolling over 70 million students while in less than two decades, India has managed to create additional capacity for over 40 million students. At present, higher education sector witnesses spending of over Rs 46,200 crore (US\$ 6.96 billion), and it is expected to grow at an average annual rate of over 18 per cent to reach Rs 232,500 crore (US\$ 35.03 billion) in next 10 years.India's IT firms are working with academic institutions and setting up in-house institutes to groom the right talent as these companies move to Social media, Mobility, Analytics and Cloud (SMAC) technologies.

"The cloud brings a lot of advantages," says AravindSitaraman, president, Inclusive Growth at Cisco. "It lowers costs, provides a degree of scalability and keeps the complexity in a central location." His company has developed an integrated hardware-software cloud solution for education, called Cisco Education Enabled 
Development (CEED) 2700. Code-named Dwara, this all-in-one box promises to reduce the cost of implementing cloud solutions to a dollar per child per month.

Review of Literature: Researchers have different viewpoints about cloud learning in education sector.

1. Bo,Dong et al (7) has presented an e-learning frame work called blue-sky cloud framework in which physical machines have been virtualized and allocated on demand for e-learning systems.It also solves the challenges faced by e-learning systems. It also consists of three layers such as the virtual infrastructure, capability and data caching layer. It improves the availability performance and scalability of e-learning system.

2. Madhumathi, (2)“cloud computing based e-learning provides anywhere, anytime and any device learning. Cloud learning will be beneficiated by every students, faculties, administrators and research scholars. This framework addresses the services and deployment of cloud in a new dimension and each layer specifies the essential components neededto construct an academic cloud in a university".

3. Prof.Abu El- Ala,cloud computing for solving e-learning problems. He proposed environment focuses on designing and monitoring educational enviroment based on reusing the existing web tools, techniques and services to provide browser- based application.

4. Deepanshu, Institute of technology India, focused on e-learning application model based on cloud computing will not stop its pace to proceed. As the cloud computing technologies become more sophisticated and the applications of cloud computing becomes increasingly widespread, e-learning will certainly usher in a new era of cloud computing.

\section{Background of Digital Education}

Printing press changed the world of education forever. Six centuries later we are undergoing another transformation and this time everything is going digital. Leading this second wave of technology backed empowerment; Educomp has taken education from the paper to the pixel.

As a pioneer in bringing digital education to the Indian classroom, Educomp has brought about a radical change in the traditional ways of teaching with its exemplary innovations in the digital space.Educomp takes pride in having a legacy of introducing latest technology based solutions to the schools. As a thought leader in some of the products designed for schools, Educomp products like the smartclass have become iconic and often synonymous with digital classrooms. Educompsmartclass is known to have brought about a radical change in the traditional ways of teaching with its exemplary innovations in the space of digital content usage in the classroom. Science at senior grades can now become even more exciting with atoms bursting at an arm length with Educomp's 3D Lab. Keeping in mind the need for a global proficiency in English, the Educomp English Mentor Lab has been specially designed to combine a unique methodology with language learning tools that enable students to internalise sentence patterns and practice reading, writing and verbal skills on their own. Educomp Smart Schools form the next generation of Educomp's learning suite of products. The first of its kind in the world, it offers a bouquet of education solutions that comprehensively assist schools to leap frog towards an enhanced paradigm of teaching and learning. The quality of education and increasing learning outcomes are the offshoot of amalgamation of never before features, allowing the schools to integrate, nourish, create and enhance a 360 degree relationship with all stakeholders while keeping the student at the center of the learning experience. With League India Schools, educomp soared further with not just a basket of best in the class education solutions but also transformational best practices that allow schools to adopt "The League India" stamp. As a value added distributor to fliplearn.com, Educomp is on a firm straddle of the 21st Century learning platform marking the future of Education, with ubiquitous flip from traditional to digital tools that seamlessly hop from mobiles to laptops and tablets.

Here's a bouquet of product offerings for Schools to take the big Leap

EducompSmartclass: Educompsmartclass is the industry pioneer in the use of rich multimedia content as a teaching tool inside the classrooms in India. It's a revolutionary in-classroom technology leveraging a large repository of digital content across virtually all subjects from kindergarten to grade 12. Educompsmartclass has been endorsed by detailed testing from Dun \& Bradstreet.

English Mentor: English mentor is an English Language Lab which has been meticulously designed keeping in mind the education requirements of English language learners from grade one to ten, such that the understanding of the language and its fundamentals get imbibed in an engrossing scenario. It offers a self-paced environment that allows users to correct mistakes, practice correct pronunciation and move on towards coaching in public speaking with confidence.

EducompSmartclass 3d Lab:With 3 D lab complex Concepts become easier to comprehend. When abstract concepts come alive, students can almost feel that they are a part of the subject itself. 
Educomp Insight: 'Insight' is a scientifically designed assessment system that evaluates the academic competency of the student. Insight assesses students on 10 skills and 35 sub skills making it one of the most comprehensive assessment and counselling systems.

Educomp Smart School: A first of its kind comprehensive School Solutions through which schools enhance the quality of learning providing path-breaking features. It allows schools to create, integrate, nourish and enhance a 360 degree relationship with all the stakeholders while keeping the student at the centre of the learning experience.

League India: The vision for league INDIA is to build a vast fraternity of new age schools, recognized and respected for their distinct positioning and adoption of well researched best practices that encompass the League INDIA institutions.

Uniclass: Edu compUniClass is a teaching and learning system where a user can access a large repository of rich multimedia content mapped to curriculum. Uniclass is available for Nursery to Grade twelve. The UniClass device is similar to a set-top box and can be connected to a television, a projector or any other display appliance. It gives students an engaging and interesting way to learn. Easy to set up and maintain, EducompUniClass is a simple and cost effective way for schools on a budget and users who can afford their personal content library.

Role of Cloud Learning:India's IT firms are working with academic institutions and setting up in-house institutes to groom the right talent as these companies move to Social media, Mobility, Analytics and Cloud (SMAC) technologies.

"The cloud brings a lot of advantages," says AravindSitaraman, president, Inclusive Growth at Cisco. "It lowers costs, provides a degree of scalability and keeps the complexity in a central location." His company has developed an integrated hardware-software cloud solution for education, called Cisco Education Enabled Development (CEED) 2700. Code-named Dwara, this all-in-one box promises to reduce the cost of implementing cloud solutions to a dollar per child per month.

The Karnataka government already uses Dwara in a handful of rural schools, and to train teachers in some districts. Private schools such as the Oakridge International chain and technical education institutions such as the Nettur Technical Training Foundation have also adopted this technology.

Some organisations implement cloud solutions with their existing bandwidth, and without extra hardware. Bangalore-based Aurus Network's CourseHub is one such low-bandwidth video capture, management and distribution platform targeted at educational institutes. Others, such as Gate Forum, use the cloud to help final-year engineering students in small cities like Agra to prepare for the annual Graduate Aptitude Test in Engineering. But the largest on-ground implementation is NIIT's Cloud Campus, now available in over 150 centres nationwide.

NIIT gives students access to its faculty as well as round-the-clock availability of labs, course content and collaborative platforms. So while hundreds of students enrol in small towns such as Bagdogra, West Bengal, and Haldwani, Uttarakhand, to learn from the best faculty, in big cities ambitious 20 -year-olds such as RidhimaKapoor may find that the Cloud Campus gives them time, for example, to do an evening course in commerce at Delhi University.

NIIT chief executive G. Raghavan says their cloud campus basically addresses the need for flexibility and learning on demand. "Flexibility will be in terms of when, what and how to learn," he says. "This will be different for each person, so we have to get an optimal mix of pedagogy to get learning effectiveness".

His colleague, NIIT Imperia Executive Vice-President Udai Singh, says that the cloud enables instructors to get valuable data about the level at which students are able to understand a point. "This data point is not possible in a Physical World".

But how do you manage traffic when students from multiple centres are listening to a single teacher? Singh says more centres don't mean you get more questions than you would in a single classroom. "Once you have reached a critical mass of students, the questions depend on what is being taught," he says. "So just a finite number of questions emerge, and that is enough for the others to understand." He adds that the data quickly helps teachers pre-empt questions and emphasise what they teach.

There is much debate on whether a virtual teacher can actually replace or fill in for hundreds of others. Singh says: "If you are looking at technology replacing teachers, we are missing the point. Tech is a force multiplier that can increase the scope and impact of a teacher". However, Sameer Brahmachari, Director General of the Council of Scientific \& Industrial Research (CSIR), says technology has blurred the lines that separate teacher and student. "My experience with open source drug discovery has shown that groups of students who are monitored are the weakest, he says". 
According to AbhinavDhar, director for K-12 at Educomp Solutions, more than 12,000 schools across 560 districts in India have adopted Smartclass. More importantly, the number is growing at almost 20 schools a day. On average, in each of these schools eight classrooms are using Smartclass.

\section{Future Classrooms under the Impact of Cloud Learning:}

There is no doubt about a great future of education in India. Yet, the way to reach out to a great future still has to be thought about. Cloud is emerging as the medium to make quality education accessible to all.

Presently, a number of our schools suffer from a low quality education delivery, primarily due to short handed staff, inefficient infrastructure, tiny classrooms and lack of teachers. Cloud computing solutions can solve many of these problems through online lesson planning tools, automating school management process, and online homework submission etc. Cloud technology will eventually ensure that the present 'factory' model of education disappears from the systems. This assurance comes from the fact that cloud solutions do not require any traditional education tools like classrooms, teachers, textbooks etc. By virtue of cloud computing, students in the near future will have anytime and anywhere access to their classrooms and teachers. The future of education is all about anytime anywhere access to content and learning. Therefore, cloud computing has got a prominent role to play in the classrooms of the future.

Traditionally, lesson planning used to be done on paper in the form of teacher's diaries. It also required the teachers to either carry the diaries around or be present at the school premises. With lesson planning facility on cloud, teachers can define lesson plans for various subjects along with the number of periods required to complete the course material - from anywhere and at anytime. On-demand access to lesson plans for parents leads to better communication and well-managed education delivery. Since automation software are on reputed cloud services such as AmazonWeb Services and Google Cloud, concerns about the security of the system and reliability is taken care of.

From schools, let's move to colleges. Many colleges do not have sufficient hardware or software to give students a complete learning experience. This problem is especially pronounced in the technical fields. However, with SaaS, a limited budget will still allow students access to the latest technologies on offer. Simulating those complex weather patterns and running those complicated algorithms will no longer be something that only students at the top-of-the institutions can do. In other words, cloud computing can democratize education.

Ultimately, technology is going to have a significant impact on teaching and learning. The power of the cloud and more consumer-orientated devices are going to make anytime, anywhere learning more commonplace and accessible to all. Furthermore, with access to free, or very cost effective, learning content now becoming ubiquitous, the role of the teacher is going to evolve and become more important than ever

In the Indian education landscape, technology is often considered as an invitation to huge investments in computer peripherals and their maintenance. But thanks to cloud technology that the educational institutes need not invest in any servers or other peripherals. All they need is a computer with a web browser and an internet connection.

Since technology has been a constant part of our lives, cloud based educational tools are a great way to teach a generation that has been raised on computers. This new generation can learn new things and in new ways that those of us who are now adults could never have dreamed of.

The cloud is poised to revolutionize the educational sector, and schools and learning institutions would be wise not to write off the cloud as just a business tool. The future opportunities for success or failure of students could rest in the cloud.

India has made an impressive effort in following the global trend by digitalising its education system.

Educational Systems are changing rapidly their characteristics now a day. An earlier conventional education system was main medium at teaching and learning. But several internet and problems lead the cause of other educational mode. Initially private educational mode was originated to some of the people who are not able to join in regular class room based education, due to lower marks, employment, Fee Structure, Geographical conditions and working condition, time schedule universities are allowed to run private education mode, where student just appear examination for the degree based on preparation of his/her self. This teachinglearning process called Distance Education/cloud campus or E-learning. Internet and computer play an important role for distance education and online education. Today class, reference material, library, group discussion and counselling and other activities fully depend on and several computing tools, techniques and mechanism. Cloud computing is an important technology responsible for healthy online and distance education many ways.

Today, students can order books online and may never visit the college bookstore. The card catalogue is long gone from the library, and today's research tools are more targeted and more efficient. Today's college library is often home to computer labs and tutor centres. 
Tutoring and counselling sessions can now be conducted remotely. India is a vast country with much diversity - in culture, language, heritage etc. and so is its education system. We have schools with all digitised air-conditioned classrooms as well as the transportation; there are schools which believe in emphasising on value education by following Guru Kul system, where students are taught under the trees despite of having world-class infrastructure. At the same time there are schools which emphasise on books and physical development of students by conducting in-house activities whereas others can afford international exchange programs and have been able to send their students even to NASA. At the same time we have schools where students struggle for books.

India holds an important place in the global education industry. The country has more than 1.4 million schools with over 227 million students enrolled and more than 36,000 higher education institutes. India has one of the largest higher education systems in the world. However, there is still a lot of potential for further development in the education system.

India's online education market size is expected to touch US\$ 40 billion by 2017. An RNCOS report titled, 'Booming Distance Education Market Outlook 2018' expects the distance education market in India to grow at a compound annual growth rate (CAGR) of around 34 per cent during 2013-14 to 2017-18. Moreover, the aim of the government to raise its current gross enrolment ratio to 30 per cent by 2020 will also boost the growth of the distance education in India.

The education sector in India is poised to witness major growth in the years to come as India will have world's largest tertiary-age population and second largest graduate talent pipeline globally by the end of 2020 . As of now the education market is worth US\$ 100 billion. Currently, higher education contributes 59.7 per cent of the market size, school education 38.1 per cent, pre-school segment 1.6 per cent, and technology and multimedia the remaining 0.6 per cent.

Higher education system in India has undergone rapid expansion. Currently, India's higher education system is the largest in the world enrolling over 70 million students while in less than two decades, India has managed to create additional capacity for over 40 million students. At present, higher education sector witnesses spending of over Rs 46,200 crore (US\$ 6.96 billion), and it is expected to grow at an average annual rate of over 18 per cent to reach Rs 232,500 crore (US\$ 35.03 billion) in next 10 years. India's IT firms are working with academic institutions and setting up in-house institutes to groom the right talent as these companies move to Social media, Mobility, Analytics and Cloud (SMAC) technologies.

"The advent of saving option has drastically affected the Printing press industry and changed the world of education forever. Six centuries later we are undergoing another transformation and this time everything is going digital. Leading this second wave of technology backed empowerment; Educomp has taken education from the paper to the pixel.

As a pioneer in bringing digital education to the Indian classroom, Educomp has brought about a radical change in the traditional ways of teaching with its exemplary innovations in the digital space. Educomp takes pride in having a legacy of introducing latest technology based solutions to the schools. As a thought leader in some of the products designed for schools, Educomp products like the smartclass have become iconic and often synonymous with digital classrooms. Educompsmartclass is known to have brought about a radical change in the traditional ways of teaching with its exemplary innovations in the space of digital content usage in the classroom. Science at senior grades can now become even more exciting with atoms bursting at an arm length with Educomp's 3D Lab. Keeping in mind the need for a global proficiency in English, the Educomp English Mentor Lab has been specially designed to combine a unique methodology with language learning tools that enable students to internalise sentence patterns and practice reading, writing and verbal skills on their own. Educomp Smart Schools form the next generation of Educomp's learning suite of products. The first of its kind in the world, it offers a bouquet of education solutions that comprehensively assist schools to leap frog towards an enhanced paradigm of teaching and learning. The quality of education and increasing learning outcomes are the offshoot of amalgamation of never before features, allowing the schools to integrate, nourish, create and enhance a 360 degree relationship with all stakeholders while keeping the student at the center of the learning experience. With League India Schools, educomp soared further with not just a basket of best in the class education solutions but also transformational best practices that allow schools to adopt "The League India" stamp. As a value added distributor to fliplearn.com, Educomp is on a firm straddle of the 21 st Century learning platform marking the future of Education, with ubiquitous flip from traditional to digital tools that seamlessly hop from mobiles

Educompsmartclass is the industry pioneer in the use of rich multimedia content as a teaching tool inside the classrooms in India. It's a revolutionary in-classroom technology leveraging a large repository of digital content across virtually all subjects from kindergarten to grade 12. Educompsmartclass has been endorsed by detailed testing

English mentor is an English Language Lab which has been meticulously designed keeping in mind the education requirements of English language learners from grade one to ten, such that the understanding of the 
language and its fundamentals get imbibed in an engrossing scenario. It offers a self-paced environment that allows users to correct mistakes, practice correct pronunciation and move on towards coaching in public speaking. A first of its kind comprehensive School Solutions through which schools enhance the quality of learning providing path-breaking features. It allows schools to create, integrate, nourish and enhance a 360 degree relationship

The vision for league INDIA is to build a vast fraternity of new age schools, recognized and respected for their distinct positioning and adoption of well researched best practices that encompass the League INDIA institutionsEdu comp UniClass is a teaching and learning system where a user can access a large repository of rich multimedia content mapped to curriculum. Uniclass is available for Nursery to Grade twelve. The UniClass device is similar to a set-top box and can be connected to a television, a projector or any other display appliance. It gives students an engaging and interesting way to learn. Easy to set up and maintain, EducompUniClass is a simple and cost effective way for schools on a budget and users who can afford their personal content library.

\section{Role of Cloud Learning:}

India's IT firms are working with academic institutions and setting up in-house institutes to groom the right talent as these companies move to Social media, Mobility, Analytics and Cloud (SMAC) technologies.

"The cloud brings a lot of advantages," says AravindSitaraman, president, Inclusive Growth at Cisco. "It lowers costs, provides a degree of scalability and keeps the complexity in a central location." His company has developed an integrated hardware-software cloud solution for education, called Cisco Education Enabled Development (CEED) 2700. Code-named Dwara, this all-in-one box promises to reduce the cost of implementing cloud solutions to a dollar per child per month.

The Karnataka government already uses Dwara in a handful of rural schools, and to train teachers in some districts. Private schools such as the Oakridge International chain and technical education institutions such as the Nettur Technical Training Foundation have also adopted this technology.

Some organisations implement cloud solutions with their existing bandwidth, and without extra hardware. Bangalore-based Aurus Network's CourseHub is one such low-bandwidth video capture, management and distribution platform targeted at educational institutes. Others, such as Gate Forum, use the cloud to help final-year engineering students in small cities like Agra to prepare for the annual Graduate Aptitude Test in Engineering. But the largest on-ground implementation is NIIT's Cloud Campus, now available in over 150 centres

NIIT gives students access to its faculty as well as round-the-clock availability of labs, course content and collaborative platforms. So while hundreds of students enrol in small towns such as Bagdogra, West Bengal, and Haldwani, Uttarakhand, to learn from the best faculty, in big cities ambitious 20-year-olds such as RidhimaKapoor may find that the Cloud Campus gives them time, for example, to do an evening course in commerce at Delhi University.

NIIT chief executive G. Raghavan says their cloud campus basically addresses the need for flexibility and learning on demand. "Flexibility will be in terms of when, what and how to learn," he says. "This will be different for each person, so we have to get an optimal mix of pedagogy to get learning effectiveness".

His colleague, NIIT Imperia Executive Vice-President Udai Singh, says that the cloud enables instructors to get valuable data about the level at which students are able to understand a point. "This data point is not possible in a Physical World".

But how do you manage traffic when students from multiple centres are listening to a single teacher? Singh says more centres don't mean you get more questions than you would in a single classroom. "Once you have reached a critical mass of students, the questions depend on what is being taught," he says. "So just a finite number of questions emerge, and that is enough for the others to understand." He adds that the data quickly helps teachers pre-empt questions and emphasise what they teach.

There is much debate on whether a virtual teacher can actually replace or fill in for hundreds of others. Singh says: "If you are looking at technology replacing teachers, we are missing the point. Tech is a force multiplier that can increase the scope and impact of a teacher". However, Sameer Brahmachari, Director General of the Council ofThere is no doubt about a great future of education in India. Yet, the way to reach out to a great future still has to be thought about. Cloud is emerging as the medium to make quality education accessible to all.

Presently, a number of our schools suffer from a low quality education delivery, primarily due to short handed staff, inefficient infrastructure, tiny classrooms and lack of teachers. Cloud computing solutions can solve many of these problems through online lesson planning tools, automating school management process, and online homework submission etc. Cloud technology will eventually ensure that the present 'factory' model of education disappears from the systems. This assurance comes from the fact that cloud solutions do not require any traditional education tools like classrooms, teachers, textbooks etc. By virtue of cloud computing, students in the near future will have anytime and anywhere access to their classrooms and teachers. The future of 
education is all about anytime anywhere access to content and learning. Therefore, cloud computing has got a prominent role to play in the classrooms of the future.

Traditionally, lesson planning used to be done on paper in the form of teacher's diaries. It also required the teachers to either carry the diaries around or be present at the school premises. With lesson planning facility on cloud, teachers can define lesson plans for various subjects along with the number of periods required to complete the course material - from anywhere and at anytime. On-demand access to lesson plans for parents leads to better communication and well-managed education delivery. Since automation software are on reputed cloud services such as AmazonWeb Services and Google Cloud, concerns about the security of the system and reliability is taken care of.

From schools, let's move to colleges. Many colleges do not have sufficient hardware or software to give students a complete learning experience. This problem is especially pronounced in the technical fields. However, with SaaS, a limited budget will still allow students access to the latest technologies on offer. Simulating those complex weather patterns and running those complicated algorithms will no longer be something that only students at the top-of-the institutions can do. In other words, cloud computing can democratize education.

Ultimately, technology is going to have a significant impact on teaching and learning. The power of the cloud and more consumer-orientated devices are going to make anytime, anywhere learning more commonplace and accessible to all. Furthermore, with access to free, or very cost effective, learning content now becoming ubiquitous, the role of the teacher is going to evolve and become more important than ever

In the Indian education landscape, technology is often considered as an invitation to huge investments in computer peripherals and their maintenance. But thanks to cloud technology that the educational institutes need not invest in any servers or other peripherals. All they need is a computer with a web browser and an internet connection.

Since technology has been a constant part of our lives, cloud based educational tools are a great way to teach a generation that has been raised on computers. This new generation can learn new things and in new ways that those of us who are now adults could never have dreamed of.

The cloud is poised to revolutionize the educational sector, and schools and learning institutions would be wise not to write off the cloud as just a business tool. The future opportunities for success or failure of students could rest in the cloud

Educational Systems are changing rapidly their characteristics now a day. An earlier conventional education system was main medium at teaching and learning. But several internet and problems lead the cause of other educational mode. Initially private educational mode was originated to some of the people who are not able to join in regular class room based education, due to lower marks, employment, Fee Structure, Geographical conditions and working condition, time schedule universities are allowed to run private education mode, where student just appear examination for the degree based on preparation of his/her self. This teachinglearning process called Distance Education/cloud campus or E-learning. Internet and computer play an important role for distance education and online education. Today class, reference material, library, group discussion and counselling and other activities fully depend on and several computing tools, techniques and mechanism. Cloud computing is an important technology responsible for healthy online and distance education many ways.

Today, students can order books online and may never visit the college bookstore. The card catalogue is long gone from the library, and today's research tools are more targeted and more efficient. Today's college library is often home broadly, students can now enrol in and complete a degree program entirely online, without setting foot in the city or state of the institution they attend. And while these online courses and programs replicate a more "traditional" college experience, with restricted class sizes and specific requirements for attending, some prestigious institutions are now using technology platforms to open up their courses to the world, teaching tens of thousands of students at once. This type of course is commonly referred to as a "massive open online course," or MOOC.

But has this been a success at all the levels of society in India or has been a reality for some and just a mirage for others. Here, we shall discuss the impact of technology on Indian education sector at three levels i.e. urban private schools, rural and non-privatised schools and academicians.

\section{Impact on Urban Private Schools and Institutions:}

Like any other sector Globalisation and revolution in information and communication technology brought many changes to education sector too. Arrival of Pearsons and Educomp introduced a new experience in classroom with 3D presentations and Video-conferencing with experts inrespective fields.

Teachers are able to beam well-known education leaders and policy makers into the classroom using video conferencing technology . It is almost like being in the same room with people whom the students would otherwise likely not have a chance to meet. Students have their laptop computers, electronic tablets, and cell 
phones on during class, taking notes and searching the Internet for the latest information on topics that come up in our classroom discussions.

Between face-to-face class meetings, the students and faculty engage in lively online discussions on topics that are assigned or in response to questions that are asked, usually about hot issues under discussion Every student in the class is engaged in the discussions and exchanges with the faculty and with colleague students. This new environment is a significant departure from the lecture hall of the 1960s and 70s, where rigid seating made it almost impossible for students to interact with one another and where students in the back row may never have asked a question or been called upon. Today, between face-to-face meetings, we sometimes schedule a virtual class session, often involving a guest presenter, whom the students can see and with whom they can interact. These sessions can be recorded and links to the sessions can be placed on the course learning management system.

\section{Impact onAcademicians:}

Today's educational technology has almost forced a greater engagement between faculty and students and among students. It is helping faculty to focus more on the learning environment for their students. But it has also changed the way colleges do business. In the 1980s, when I was at Palomar College, we moved away from in-person registration lines to phone-in registration - and then, in the 1990s, to online registration.

But are we ready for this where we focus more on ranks in university than what we actually know and can deliver.

Indian education regulatory system puts a limitation on the scope of digital education. Students are worried about their grades and restrict themselves to the prescribed curriculum, faculties are in hurry to complete the syllabus, management concern is to secure top ranks in the university.

An online degree or course is still not recognized in India.

Online education in India has another major challenge that there is no proper grooming of the students on soft skill and personality development dueto which it has less preference in job market. Main objective of education is empowerment .SmritiIrani introduced apps to empower students and parents. But is this objective met? PuttingNCERT books online is certainly appreciated butmost of the apps still remain only a hype which prove to be useful for digital natives but not by digital immigrants.

\section{Conclusion}

The proponents of technology have not gone far enough. Education cannot change bygetting individual instructors to adopt any technology. Individual instructors are frozen by curriculum, work load and regulatory agencies. They must always balance the equation of deeper learning versus time consumed. The rationale for the impact of digital technology on teaching and learning needs to be clear:

1. Will learners work more efficiently, more effectively, more intensively? Will the technology help them to learn for longer, in more depth, more productively? Or will the teacher be able to support learners more efficiently or more effectively?

2. The role of technology in learning should be identified: Will it help learners gain access to learning content, to teachers or to peers? Will the technology itself provide feedback or will it support more effective feedback from others, or better self-management by learners themselves?

3. Technology should support collaboration and effective interaction for learning: The use of computer and digital technologies is usually more productive when it supports collaboration and interaction, particularly collaborative use by learners or when teachers use it to support discussion, interaction and feedback.

4. Teachers and/or learners should be supported in developing their use of digital technology to ensure it improves learning. Training for teachers (and for learners), when it is offered, usually focuses on technology skills in using the equipment. This is not usually sufficient to support teachers and pupils in getting the best from technology in terms of their learning. On-going professional development and support to evaluate the impact on learning is likely to be required.

5. Identify what learners and teachers will stop doing: The use of digital technology is usually more successful as a supplement rather than as a replacement for usual teaching. Technology is not introduced into a vacuum. It is therefore important to identify carefully what it will replace or how the technology activities will be additional to what learners would normally experience.

To make online education successful in India we need to modify the entire education sector and the mind-set of the employers as it has not gained their favour yet. We are yet to travel miles before we reach the stage where we can proudly say certificates and degrees are just piece of papers for us we value knowledge of the person.

Hence to meet the requirements of Indian students we propose hybrid model where there should be a combination of physical presence of the teacher and technology. 


\section{References}

[1]. https://www.ncsl.org/portals/1/documents/educ/item013161.pdf

[2]. http://eprints.ioe.ac.uk/628/1/Laurillard2008Digital_technologies.pdf

[3]. http://www.greenbaypressgazette.com/story/money/2014/10/21/technologys-impact-higher-education/17693719/

[4]. Https/ Indian express/ can digital educate India Written by Maya Escueta Updated: Aug 17, 2015.

[5]. KiranYadav, Role of cloud computing in education, "International journal of innovation research in computer and communication engineering".

[6]. A.S. Sathish Kumar, emerging Technology on smart Class teaching in school education A literature review -IJSR Vol 3,issue8 Aug 2014.

[7]. International journal on recent and innovation trends in computing and communication volume3, issue2. 